Fixed Point Theory, 21(2020), No. 2, 481-494

DOI: $10.24193 /$ fpt-ro.2020.2.35

http://www.math.ubbcluj.ro/ nodeacj/sfptcj.html

\title{
NONEXPANSIVE MAPPINGS AND CONTINUOUS $s$-POINT SPACES
}

\author{
SHAHROKH GHASEMZADEHDIBAGI*, MEHDI ASADI** AND SOMAYEH HAGHAYEGHI*** \\ *Department of Mathematics, Karaj Branch, Islamic Azad University, Karaj, Iran \\ E-mail: sh.ghasemzadeh@kiau.ac.ir \\ **Department of Mathematics, Zanjan Branch, Islamic Azad University, Zanjan, Iran \\ E-mail: masadi@iauz.ac.ir (Corresponding author) \\ *** Department of Mathematics, Karaj Branch, Islamic Azad University, Karaj, Iran \\ E-mail: s.haghayeghi@kiau.ac.ir
}

Abstract. Here, the concept of continuous $s$-point space is introduced in $b$-metric spaces. Under suitable assumptions, these spaces are absolute retracts and a generalization of the continuous midpoint spaces. Moreover, an important fixed point theorem is proved for nonexpansive mappings in continuous $s$-point spaces.

Key Words and Phrases: Continuous $s$-point spaces, $b$-metric spaces, nonexpansive mappings. 2010 Mathematics Subject Classification: 47H10, 51D99, 47H10.

\section{REFERENCES}

[1] M. Asadi, B.E. Rhoades, H. Soleimani, Some notes on the paper "The equivalence of cone metric spaces and metric spaces", Fixed Point Theory and Applications 2012, 2012:87.

[2] H.F. Buhnenblust, S. Karlin, ON the theorem of Ville, Contributions to the Theory of Games, Princeton, 1(1950), 155-160.

[3] D. Burago, Y. Burago, S. Yvanov, A Course in Metric Topology, Graduate Text in Mathematics, American Mathematical Society, 33(2001).

[4] S. Czerwik, Nonlinear set-valued contraction mappings in b-metric spaces, Atti Sem. Mat. Univ. Modena, 46(2)(1998), 263-276.

[5] J. Dugundji, Locally equiconnected spaces and absolute neighborhood retracts, Fund. Math., 57(1965), 187-193.

[6] Y. Feng, W. Mao, Equivalence of cone metric spaces and metric spaces, Fixed Point Theory, 11(2010), no. 2, 259-264

[7] A. Hojat Ansari, P. Kumam, B. Samet, A fixed point problem with constraint inequalities via an implicit contraction, J. Fixed Point Theory Appl., 19(2017), no. 2, 1145-1163.

[8] C. Horvath, A note on metric spaces with continuous midpoints, Annals of the Academy of Romanian Scientists, Series on Mathematics and its Applications, 1(2)(2009), 252-288.

[9] P. Kumam, N. Van Dung, V.T. Le Hang, Some equivalences between cone b-metric spaces and b-metric spaces, Abstract Applied Anal., Vol. 2013, Art. ID 573740, 8 pages.

[10] S. Phiangsungnoen, P. Kumam, On stability of fixed point inclusion for multivalued type contraction mappings in dislocated b-metric spaces with application, Math. Meth. Appl. Sci. 2018, 114, https://doi.org/10.1002/mma.4871. 
Received: December 20, 2017; Accepted: September 30, 2018. 
